\title{
Roald Amundsen's Arctic research role in the development of Geophysics: the case of the 1903-1906 expedition
}

\author{
Valeriy Kramskiy ${ }^{1}$, Ekaterina Samylovskaya ${ }^{2, *}$ and Stefano Maria Capilupi $^{3}$ \\ ${ }^{1}$ Student, Saint Petersburg Mining University, 199106, 2, 21st Line, Saint Petersburg, Russia \\ ${ }^{2}$ Candidate of History, assistant, Department of History, Saint Petersburg Mining University, 199106, 2, 21st Line, , Saint Petersburg \\ Russia \\ ${ }^{3} \mathrm{PhD}$ (Philosophy), PhD (Philology), Subject Expert, Sapienza University of Rome, 00185, 5, Piazzale Aldo Moro, Rome, Italy
}

\begin{abstract}
The paper discusses Roald Amundsen's discoveries in the sphere of knowledge about the Earth's magnetic field, made during the Arctic expedition of 1903-1906. A historical overview of previous discoveries made by scientists in the process of studying Geomagnetism is given. The research is based on the study and analysis of R. Amundsen's memoirs about the expedition. The authors consistently consider the stages of the expedition along the Northwest passage in 1903-1906 and its results. The significance of the geomagnetic characteristics obtained in this expedition is shown. Attention is paid to the phenomenon of magnetic poles drift, and the process of its discovery is described in detail. Amundsen's discovery of magnetic drift gave an invaluable impetus for further Geomagnetism development, which is also briefly considered. Observations made by Roald Amundsen helped to take a new look at the existing scientific picture of the world, to challenge the traditional model of the Earth structure and to construct a new and, in many ways, revolutionary scheme. As a result of the research, the authors of the paper come to the conclusion that the expedition of 1903-1906 is one of the greatest scientific breakthroughs of that time, also in the sphere of Geophysics. Scientists processed the recorded characteristics of the magnetic field in the Arctic until the $30 \mathrm{~s}$ of the $20^{\text {th }}$ century. This huge flow of data allowed to supplement the existing maps with magnetic declination and inclination readings in the studied area, and thus to simplify further development of the Arctic region.
\end{abstract}

\section{Introduction}

Russian researchers practically did not consider the issue of the historical development of geophysical knowledge. Moreover, historians have not studied the sphere of Geomagnetism in details. At the same time, some works were written to give a general idea of the process of studying the Earth's magnetic field. An example of such research is A. F. Burkov's monograph, in which the author outlined the main discoveries in the sphere of magnetism [1]. However, many names and discoveries made by them were not reflected in this work, neither in similar books by L. V. Tarasov and B. M. Yanovsky [2], [3]. In turn, we will try to trace the main stages in the development of research in the sphere of magnetism and to closely analyse the expedition along the Northwest Passage, made by Roald Amundsen in 1903-1906 and not reflected in Russian historiography from the point of view of geophysical observations. We will also try to give a general idea of the scientific significance of these studies and on how the knowledge obtained in these expeditions can be applied in modern technology.

\footnotetext{
* Corresponding author: katerina-samylovskaya88@yandex.ru
}

\section{History of the research development in the sphere of Geomagnetism}

According to L. V. Tarasov's work, the study of Geomagnetism dates back to the appearance of the first navigation device, which operation principle was based on the magnet interaction with the external field [3, p. 8]. Even in the times of Ancient China, people constructed the first prototype of a modern compass and began to actively use this device in navigation. The precise orientation of the magnetic needle made it possible to easily travel long distances, following the direction of movement.

However, over time, technology developed and travel routes became longer. At the same time, the number of cases when the compass gave incorrect readings also increased. Ships and caravans went astray.

A justification for this phenomenon was soon obtained. The shift of the arrow in relation to the true North direction occurred due to the inhomogeneity of the magnetic field surrounding the compass. Large bodies with pronounced magnetic properties created interference and generated declination and inclination - 
displacements of the compass needle vertically and horizontally in relation to the North direction. These characteristics of the magnetic field were first recorded in the ship logs by Ch. Columbus in 1492. This fact is mentioned by O. M. Raspopov and V. V. Meshcheryakov in their paper "The $16^{\text {th }}$ century - the first definitions of the geomagnetic field elements on the Russian territory: Kola Peninsula and Arkhangelsk region" [4, p. 74]. Later, such magazines were distributed both in Europe and in Asia. Each navigator tried to measure the characteristics of the geomagnetic field during the expedition.

Magnetic surveys were started almost immediately after Columbus discovered the magnetic declination. However, for about two hundred years (in the $16^{\text {th }}-17^{\text {th }}$ centuries), they were random. Navigators who needed to know the magnetic declination in the places where their path lay performed them [2, p. 18].

Scientists of that time also referred to the magnetic fields of permanent magnets in their attempts to explain the very principle of the compass. They assumed that there is a large deposit of magnetic ore in the Northern latitudes, which generates a strong magnetic field able to direct the compass needle. There were even geographical maps based on this hypothesis. In 1569, Gerard Mercator published an innovative cartographic projection of the Arctic region. It depicted a black rock with a circumference of 33 nautical miles. This work, important for the $16^{\text {th }}$ century, is mentioned in many modern papers. For example, L. K. Kildyushevskaya mentions the map, speaking of it as of the result of terrestrial magnetism research [5, pp. 106-115].

Guesses about the magnetic mountain remained relevant until the publication of the work "On the magnet, magnetic bodies and the great magnet, the Earth" by William Hilbert in 1600. In this fundamental research, a well-known English astronomer proved the nature of the Earth's magnetic field by an experiment. He rightly associated it with the strict direction of the compass needle. After grinding an orb out of magnetic ironstone (a permanent natural magnet), he held a small rod magnet near to it and saw a similar picture as in the case when the Earth interacts with the compass. This scientific work suggested a general idea of Geomagnetism: the planet is the source of the field, and magnets are the cause of its distortion [6, pp. 71-76].

After proving that the planet is a magnet, scientists and travelers were faced with the task of studying the field caused by this very magnet and recording its characteristics in different parts of the world. The research required for this purpose has become ubiquitous.

Along with the accumulation of data on declination and inclination, new features of the Earth's magnetic field were discovered, one of them was its variability. It was manifested in changes in the readings of magnetic devices over time. This feature of the geomagnetic field was recorded after comparing Edmond Halley's map of the Atlantic drawn in 1701 with the data recorded in the same region by previous years expeditions.
By the way, Halley proposed to mark the readings of magnetic devices on the map using the so-called isolines - curves, at all points of which the measured element of terrestrial magnetism has the same value. This method of recording data on the declination and inclination of the compass needle promotes the creation of a visual representation of the nature of changes in the studied indicators. It is widely used in various types of mapping and all sorts of physical quantities' distributions.

Very soon, almost the entire globe was covered with isolines describing the geomagnetic field. There were only two "white spots" - the Arctic and Antarctica. The level of seafarers' training and their technical equipment did not allow them to overcome the ice traps in these areas. The variability of the magnetic field discovered in the $18^{\text {th }}$ century was not explained either. There was not enough data available at that time to explain the causes of this phenomenon. However, everything changed in 1906, when Roald Amundsen managed to successfully return from a four-year voyage through the Northwest Passage.

\section{Roald Amundsen's 1903-1906 expedition}

To date, the world scientific and public community has unanimously recognized the importance of the Arctic region for world economic development [7, 8]. This territory, rich in various natural resources, has geostrategic significance $[9,10]$. Despite the fact that at the beginning of the $20^{\text {th }}$ century, knowledge about the region was unsystematic and fragmentary [11], it is obvious that its potential was clear for a number of researchers, among whom an important place is occupied by Roald Amundsen, who initiated an expedition along the Northwest Passage in 1903-1906.

It is easy enough to recreate all the stages of the expedition and to describe them in detail, since the Norwegian researcher immortalized all the information about it in his own books: the autobiography "My life" [12] and the historical work "Sailing the Northwest Passage on the 'Yoa' ship" [13].

The expedition was of great significance not only with its geographical research, but also with its magnetic observations, which provided scientists from all over the world with work for 20 years. Such a significant event in the scientific community provoked a great leap forward in many areas of knowledge.

In 1899, Roald Amundsen began preparing for one of the most famous expeditions in his biography: the Northwest Passage was waiting for him [14, p.21-22].

Amundsen's first step was to study Geophysics, for which he went to the German Geophysical Observatory in Hamburg. There, under the supervision of Georg von Neumeier, the researcher received all the necessary knowledge in matters related to Geomagnetism, showing fanaticism and real greed for the scientific data known at that time. 
Shortly after, he met one of his childhood idols. It was the brave discoverer Fridtjof Nansen. In the future, he repeatedly helped Amundsen, supported him in preparation for expeditions and helped with finding sponsors.

The next task was to choose a ship. Amundsen brothers' limited finances forced them to take this matter as seriously as possible, because there was no room for error.

After much thought and studying the characteristics of different types of vessels, in 1901, they chose a hunting yacht "Yoa" with a total weight of 47 tons. Having borrowed money from relatives, Roald Amundsen carried out its modernization. He installed mechanized sail winches, as well as a kerosene engine. It is worth noting that the yacht, which was unsightly at first glance, had a great advantage over the ships of previous Arctic explorers - the shape of its hull. It looked like a hen's egg, which made it invulnerable to the constantly compressing ice. Under the onslaught of ice layers, the yacht was pushed to the surface, while its integrity was not violated.

Before the main expedition, the yacht passed a series of tests in the waters of the Northern seas. The team conducted ocean observations between Norway and Greenland, which are described by P. V. Wittenburg in a book dedicated to Amundsen [15, p. 7].

In "My life" book, Roald will write: "The Arctic ocean probably rarely saw the spectacle that we presented with our ship. "Yoa" was 72 feet long, 11 feet wide, and had a shallow draft. Of course, it had only one mast, a single mainsail and several jibs. We had a good auxiliary motor, although in those days gasoline engines were still so unreliable that when we were installing our own, I was seriously warned about the danger of explosion and fire." [12]

As the departure time approached, in May 1902, "Yoa" left Tromso and anchored in Kristiania to upload a part of the purchased cargo and sled dogs. The food alone should have been enough for five long frosty years.

In the same place, the final team was established: it included Prime Lieutenant Godfred Hansen (navigator, astronomer, geologist and photographer), Anton Lund (first navigator), Peder Ristvedt (meteorologist and first engineer), Helmer Hansen (second navigator), Gustav Julvik (magnetologist), Adolf Henrik Lindstrom (cook).

Photos, as well as notes by Amundsen himself, confirm the team cast. In addition, the researcher's biographer $\mathrm{T}$. Bumann-Larsen [16, p. 122-156] describes the crew too.

The next stop was Harten harbour, where $200 \mathrm{~kg}$ of pyroxylin - an explosive that can destroy powerful ice traps - were loaded on board on 17 June.

On 25 June 1903, Roald Amundsen sailed into the Atlantic Ocean between Fair Island and the Orkney Islands on board of "Yoa". In the morning of that day, an incredibly difficult three-year voyage began.

The lack of maps made it ten times more difficult to move the ship; the team had to go by touch. The only thing that helped was the lot, which was submerged in water every hundred meters of the way. Amundsen would later write about the moments when the length of the lot rope was missing from one side, while the jagged bottom was digging into the hull of the yacht from the other.

Often, the lack of data on the bottom topography and flow features led to serious breakdowns. So, while crossing the Peel Sound, the ship got into a strong storm, because of which the rudder was broken. On that day, a strong hit against the reef damaged the anchor pins, and the yacht lost its control system.

The breakdown was solved by the same accident that caused it. A high wave tilted "Yoa", due to which the removed mounts took their original position and the steering wheel again began to perform its functions properly.

Unfortunately, such dangerous situations occurred on board regularly. So once the fuel tank leaked, which later led to a severe fire in the engine room. The result of this incident could well be a strong explosion that could destroy the ship. But even then, problems were avoided: the team cohesion and prompt actions on eliminating the fire made a great contribution to the fight against the uncontrolled elements.

Under such unfavorable conditions, when the team had to face with new problems every day, Amundsen passed through the North Atlantic, Baffin Bay, Lancaster, Barrow, Franklin, James Ross Straits, systematically conducting magnetic research. On September 9, Roald decided to stop for the winter off the South-Eastern coast of King William island, where he spent two years with his team.

It was not until March 1, 1904, when Helmer Hansen and Peder Ristvedt were able to go in search of the South magnetic pole, but due to bad weather, they returned to the camp, having failed. For the second time, on April 24, Amundsen and Hansen reached a point with coordinates $70^{\circ} 05^{\prime}$ northern latitude and $96^{\circ} 47^{\prime}$ west longitude, designated by Ross as the location of the pole. Yet the readings contradicted the 73-year-old data - the magnetic pole changed its location. However, Amundsen continued to search for it and, in the end, was a success.

The position of the magnetic pole had shifted noticeably to the North, relative to the point where it was found by James Ross' expedition. As it turned out, from 1831 till 1904, the magnetic pole had moved $46 \mathrm{~km}$ to the North. Its new coordinates were $70^{\circ} 30^{\prime}$ northern latitude and $95^{\circ} 30^{\prime}$ west longitude, as J. Baker notes in his book "History of geographical discoveries and research" [17]. This confirmed the phenomenon of pole drift, as it was later named.

Of course, the expedition did not end there. Many more bright discoveries followed: the landscape, flora and fauna of the Arctic latitudes, the life of the Eskimos, the characteristics of the magnetic field were described. All this, of course, was of great importance for the science. However, pole drift should be highlighted in particular: this phenomenon gave a new leap in the study of geomagnetic processes, in particular the inversion of magnetic poles, the study of which later made it possible 
to determine the age of rocks by their residual magnetization. Roald Amundsen's journey opened up new horizons for research for all the humanity. The sea routes opened by them, the studied relief of the ocean gave a new impetus to the development of sea transport and trade communications.

\section{Conclusion}

The 1903-1906 expedition is considered one of the greatest scientific breakthroughs of that time, and this statement is fully true for Geophysics. Scientists processed the recorded characteristics of the magnetic field in the Arctic until the 30 s of the $20^{\text {th }}$ century. This huge flow of data allowed to supplement existing maps with magnetic declination and inclination readings in the studied area, and thus to simplify further development of the Arctic region.

In turn, the discovery of magnetic pole drift also gave an invaluable boost to the study of Geomagnetism and opened up a huge list of questions for scientists. Most of them, in one way or another, were associated with the cause of the magnetic field existence.

The model of the Earth, which was constructed by William Hilbert as part of his experiment - an orb made of a permanent magnet - lost its relevance after Roald Amundsen's discovery. If the change in some field characteristics, such as declination and inclination, could be explained by studying the interaction of the magnetosphere with cosmic bodies (a striking example of the result of such interaction is magnetic storms recorded in laboratories every day), then this factor could not cause the movement of the poles. Such an effect would be possible only if a body, comparable in its size and having a magnetic field, approached the planet. Yet even in this case, the shift of the poles coordinates would occur in a fairly short period of time, which cannot be true.

This reasoning led scientists to the following conclusion: the planet cannot be described by the principle of a permanent magnet. The magnetosphere is undergoing major changes, which means that the forces which generate it are changing.

Since the interaction of the Earth with the external environment does not cause pole drift, the true cause of this natural phenomenon is a change in internal energy.

Knowledge in the sphere of nuclear physics allowed us to build a hypothesis about the structure of the Earth, in which the planet has a liquid mantle consisting of metal alloys in its structure. This assumption allows to use the principle of dynamo-machine operation, thereby revealing the cause of both the magnetosphere existence itself and the drift of the magnetic poles.

The charge-bearing flows of alloys under the influence of a hot core are heated, which is why they rise up towards the Earth's crust. At the moment of this movement, the metal loses some of its energy, cools down, and again aspires to the core. As a result of this convection motion, an electric charge moves inside the conducting circuit and a magnetic field appears.
The movement of the alloy in the Earth's body is somewhat chaotic. For this reason, the resulting magnetic field changes over time and the location of the poles changes with it.

Such a fundamental assumption, made on the basis of observations by Roald Amundsen, helped to take a new look at the existing scientific picture of the world, challenge the traditional model of the structure of the Earth and construct a new and in many ways revolutionary scheme.

\section{References}

1. A. F. Burkov, Basic discoveries and research in the sphere of magnetism, electricity, mathematics and mechanics until the end of the $17^{\text {th }}$ centur, 68 (Vladivostok, Sea State University named after admiral G.I. Nevelskiy, 2007)

2. L. V. Tarasov, Earth magnetism (Dolgoprudniy, 'Intellect' publishing house, 2012)

3. B. M. Yanovsky, Earth magnetism (Leningrad, Leningrad University Publishing house, 1978)

4. O. M. Raspopov, V. V. Meshcheryakov, The $16^{\text {th }}$ century - the first definitions of geomagnetic field elements on the Russian territory: Kola Peninsula and Arkhangelsk region, Bulletin of the Kola scientific center of the Russian Academy of Sciences. Electronic journal 1, 74-84 (2011)

5. L. K. Kildyushevskaya, Atlant of world cartography, Science from the first hands. Electronic journal 4, 106-115. Available online:: https://scfh.ru/journal/2012/nedarom-pomnit-vsyarossiya/ (2012)

6. W. Hilbert, On the magnet, magnetic bodies, and the big magnet, the Earth: translated from English, ed. by A. G. Kalashnikov (Moscow, Publishing house of the USSR Academy of Sciences, 1956)

7. Ch. Savard, A. Y. Nikulina, C. Mecemenne, E. A. Mokhova, The Electrification of Ships Using the Northern Sea Route: An Approach, Journal of Open Innovation: Technology, Market, and Complexity 6, 13-13 Available online: https://www.mdpi.com/2199-8531/6/1/13 (2020)

8. D.F. Skripnuk, K.N. Kikkas, L.K. Bobodzhanova, V.V. Lobatyuk, R.-E.A. Kudryavtseva, The Northern Sea Route: Is There Any Chance to Become the International Transport Corridor? IOP Conf. Series: Earth and Environmental Science 434, 012016 (2020)

9. A.Y. Nikulina, M.N. Kruk, Organizational and economic mechanism of oil and gas projects in the Russian arctic shelf, Journal of Internet Banking and Commerce 21 (Special Issue 6), 11 ( 2016)

10. A.M. Fadeev, F.D. Larichkin, A.E. Cherepovitsyn Features of Training of Personnel for the Arctic Marine Hydrocarbon Fields Development, Journal of Mining Institute 194, 332-338 (2011) 
11. Yu. N. Gladkiy, Sukhorukov, V.D E.A Samylovskaya, R-E.A. Kudryavtseva, A.B Almazova-Ilyina, History and perspectives for the expansion of the Russian Arctic o Ecumene, IOP Conference Series: Earth and Environmental Science 434(1), 012005 (2020)

12. R. Amundsen, My life. Available online:: https://online-knigi.com/page/1458?page $=11$

13. R Amundsen, Sailing the Northwest Passage on the ship "Yoa": translated from Norwegian, edited by M. A. Dyakonov (Leningrad, Publishing House of the Central Administration of the Northern Sea Route, 1935)

14. A. F. Treshnikov, Roald Amundsen. (St.Petersburg, Gidrometeoizdat, 1972)

15. P. V. Wittenburg, In search of Amundsen. (Leningrad, Krasnaya Gazeta, 1928)

16. T. Bumann-Larsen, Amundsen: translated from Norwegian. (Moscow, Molodaya Gvardiya, 2005)

17. J. Baker, History of geographical discoveries and research, Northwest Passage and the Canadian archipelago. Available online: http://proznania.ru/books.php/?page_id $=1158$ (2020) 